adiposity; on the other hand, the failure to show a correlation within a population might be due to excessive "noise" in the data and the possibility that only certain individuals are susceptible to the effects of dietary salt. Lastly, circumstantial evidence suggests that a reduction in salt intake may be associated with a reduction in the incidence of stroke, but properly controlled prospective studies have not been carried out. ${ }^{31}$

The introduction of a policy of restriction of dietary salt in the population has been likened to the introduction of a new drug, requiring rigorous evaluation. ${ }^{32}$ Others have argued, however, that restriction of salt is more akin to the removal of a potentially noxious agent,${ }^{4}$ that it can therefore be advocated on the basis of much less rigorous criteria, and that we should immediately recommend widespread restriction of dietary salt, particularly since a reduction of the mean blood pressure of the population of only 2 or $3 \mathrm{~mm} \mathrm{Hg}$ could produce a relatively large benefit. ${ }^{33}$ This point of view depends heavily on the belief that moderate restriction of salt is completely harmless, but in the absence of evidence to the contrary we cannot ignore the possibility that wide scale moderate restriction of salt could lead to important adverse effects within the population.

The attractions of dietary measures for controlling a disease such as hypertension are obvious, but we believe that there is insufficient evidence to advocate the use of pure restriction of dietary salt in either the treatment or the prevention of essential hypertension. We need carefully controlled, long term, prospective intervention studies in large populations in order to determine the optimal level of dietary intake of salt and to evaluate the importance of other dietary factors, particularly potassium and fats-but most importantly to determine that any proposed measures are safe.

Clinical Lecturer in Cardiovascular Medicine,

N A BooN

John Radcliffe Hospital,

Oxford OX3 9DU

Clinical Reader (Wellcome Lecturer) and

J K ARONSON

Honorary Consultant in Clinical Pharmacology,

Radcliffe Infirmary,

Oxford OX2 6HE

1 Cameron DR, Dunlop DM, Platt R, Rosenheim ML, Sharpey-Schafer EP. The rice diet in the treatment of hypertension. A report to the Medical Research Council. Lancet in the treatment
1950;ii:509-13.

2 Watkin DM, Froeb HF, Hatch FT, Gutman AB. Effects of diet in essential hypertension. II. Results with unmodified Kempner rice diet in fifty hospitalized patients. Am $\mathcal{F}$ Med 150;9:441-93.

3 Altschul AM, Grommet JK. Food choices for lowering sodium intake. Hypertension 1982;34 (suppl III): 116-20.

4 MacGregor GA. Dietary sodium and potassium intake and blood pressure. Lancet 1983;i:750-3.

5 Parijs J, Joossens JV, van der Linden L, Verstreken G, Amery AKPC. Moderate sodium restriction and diuretics in the treatment of hypertension. Am Heart $\mathcal{f}$ 1973;85:22-34

6 Morgan T, Adam W, Gillies A, Wilson M, Morgan G, Carney S. Hypertension treated by salt restriction. Lancet 1978; i:227-30.

7 Parfrey PS, Vandenburg MJ, Wright P, et al. Blood pressure and hormonal changes following alteration in dietary sodium and potassium in mild essential hypertension. Lancet 1981; ; :59-63.

8 Holly JMP, Goodwin FJ, Evans SJW, Vandenburg MJ, Ledingham JM. Reanalysis of data in two Lancet papers on the effect of dietary sodium and potassium on blood pressure. Lancet 1981;ii:1384-7.

9 Beard TC, Cooke HM, Gray WR, Barge R. Randomized controlled trial of a no-addedsodium diet for mild hypertension. Lancet 1982;ii:455-8.

10 Skrabal F, Auböck J, Hörtnagl H. Low sodium/high potassium diet for prevention of hypertension: probable mechanisms of action. Lancet 1981;ii:895-900.

11 MacGregor GA, Smith SJ, Markandu ND, Banks RA, Sagnella GA. Moderate potassium supplementation in essential hypertension. Lancet 1982;ii:567-70

12 Khaw KT, Thom S. Randomized double-blind cross-over trial of potassium on bloodpressure in normal subjects. Lancet 1982;ii:1127-9.

13 Puska P, Iacono JM, Nissinen A, et al. Controlled, randomized trial of the effect of dietary fat on blood pressure. Lancet 1983;i:1-5.

14 Anonymous. Diet and hypertension [Editorial]. Lancet 1984;ii:671-3.

15 Potter JF, Beevers DG. Pressor effect of alcohol in hypertension. Lancet 1984; i: 119-22.

16 Freestone S, Ramsay LE. Pressor effect of coffee and cigarette smoking in hypertensive patients. Clin Sci 1982;63(suppl):403-5.

17 Rouse IL, Beilin LJ, Armstrong BK, Vandongen R. Blood-pressure-lowering effect of a vegetarian diet: controlled trial in normotensive subjects. Lancet 1983;i:5-10.
18 MacGregor GA, Markandu ND, Best FE, et al. Double-blind randomized crossover trial of moderate sodium restriction in essential hypertension. Lancet 1982;i:351-5.

19 Watt GCM, Edwards C, Hart JT, Hart M, Walton P, Foy CJW. Dietary sodium restriction for mild hypertension in general practice. $\mathrm{Br} \mathrm{Med} \mathcal{J}$ 1983;286:432-6.

20 Silman AJ, Locke C, Mitchell P, Humpherson P. Evaluation of the effectiveness of a low sodium diet in the treatment of mild to moderate hypertension. Lancet $1983 ; 1: 1179-82$.

21 Richards AM, Nicholls MG, Espiner EA, et al. Blood-pressure response to moderate sodium restriction and to potassium supplementation in mild essential hypertension. Lancet 1984; ; 757-6

22 Gillum RF, Elmer PJ, Prineas RJ, Surbey D. Changing sodium intake in children. The Minneapolis children's blood pressure study. Hypertension 1981;3:698-703.

23 Simpson FO. Salt and hypertension: a sceptical review of the evidence. Clin Sci 1979;57(suppl):463-80.

24 Swales JD. Dietary salt and hypertension. Lancet 1980;i:1177-9.

25 Parfrey PS, Markandu ND, Roulston JE, Jones BE, Jones JC, MacGregor GA. Relation between arterial pressure, dietary sodium intake, and renin system in essential hypertension. BrMed f 1981;283:94-7.

26 Anonymous. Genetics, environment, and hypertension [Editorial]. Lancet 1983;i:681-2.

27 Gleibermann L. Blood pressure and dietary salt in human populations. Ecology of Food and Nutrition 1983;2:143-56.

28 Simpson FO, Waal-Manning HJ, Bolli P, Phelan EL, Spears GFS. Relationship of blood pressure to sodium excretion in a population survey. Clinical Science and Molecular Medicine 1978;55(suppl);373-5.

29 Holden RA, Ostfeld AM, Freeman DH, Hellenbrand KG, D'Atri DA. Dietary salt intake and blood pressure. JAMA 1983;250:365-9.

30 Poulter N, Khaw KT, Hopwood BEC, Mugambi M, Peart WS, Sever PS. Salt and blood pressure in various populations. $\mathcal{f}$ Cardiovasc Pharmacol 1984;6(suppl): 197-203.

31 Joossens JV, Geboers J. Salt and hypertension. Prev Med 1983;12:53-9.

32 Brown JJ, Lever AF, Robertson JIS, et al. Salt and hypertension. Lancet 1984;ii:456.

33 Rose G. Strategy of prevention: lessons from cardiovascular disease. Br Med $f$ Rose G. Strategy
$1981 ; 282: 1847-51$.

\section{Chemotherapy of Hodgkin's disease comes of age}

Twenty one years ago came the first hint of successful chemotherapy in Hodgkin's disease.' A scheme called MOPP (mustine, vincristine, procarbazine, and prednisone) led to a remarkable number of lasting responses in metastatic Hodgkin's disease. The early results have been confirmed by many other studies, and MOPP or variations on the theme now give complete remissions in $60-80 \%$ of patients with advanced (stages III and IV) Hodgkin's disease. ${ }^{2}$ Half of those patients will become long term survivors, free of disease, and are probably cured. Alternating combinations of MOPP with other regimens claimed not to be cross resistant (doxorubicin, bleomycin, vinblastine, dacarbazine) may give even better results.

In the past decade oncologists have concentrated on selecting the best treatment for each individual patient based on the outcome of clinical trials. These trials have also allowed the substantiation of prognostic factors for groups of patients treated either with radiotherapy for limited disease or chemotherapy for more advanced disease. The age of the patient, the number of individual sites of affected lymph nodes, and the size of those lymph nodes-especially the mediastinal mass-all influence the response to radiotherapy in adults treated for Hodgkin's disease. Thus elderly patients with bulky disease particularly in the mediastinum or in multiple sites will do badly.

These factors (in addition to histological picture and stage of disease) are also important for the prediction of long term survival after chemotherapy. ${ }^{4}$ Patients with nodular sclerosis and lymphocyte depleted types do badly, and those with stage IV B do less well than those with stage III. Achievement of a complete remission is a self evident prognostic factor, though very good results may be obtained from salvage treatment for non-responders and those who relapse late either by applying another chemotherapy regimen or by giving local radiotherapy when appropriate.

The treatment of Hodgkin's disease brings in its wake a 
galaxy of complications. Cytotoxic drugs have immediate side effects such as nausea and vomiting, phlebitis, alopecia, neuropathy, and late complications seen in the form of second malignancy some years after successful control of Hodgkin's disease. ${ }^{6}$ Several drugs, such as etoposide and methotrexate, are being advocated in first line treatment to lessen these effects, and several trials are attempting to find the minimum amount of chemotherapy compatible with the maximum response rate.

Radiotherapy is not without its problems either, particularly in children. Serious disturbance of growth and interference with the development of the endocrine and reproductive organs are of great concern in young patients-whose prognosis is better than that of adults. ' Furthermore, the addition of radiotherapy to chemotherapy further increases the risk of secondary malignancy in both child and adult. Not surprisingly, therefore, paediatricians have been experimenting with smaller radiotherapy fields and lower doses in children with limited disease.

An article describing long term survival of children treated for Hodgkin's disease in Britain appeared recently in the Archives of Disease in Childhood. ${ }^{8}$ The report spanned the period 1974-82 and included 80 children. The complete remission rate of these patients was $95 \%$ and their actuarial five year survival $94 \%$. The relapse free survival was $82 \%$, with a median follow up of $4 \cdot 8$ years. An encouraging feature of this report is the tendency to give chemotherapy to children with earlier stages of disease in order to avoid staging laparotomy and extended field radiation. The reduction in these fields and doses of $x$ rays prevented stunting of growth, hypothyroidism, and hypoplasia of breasts in pubertal girls. Substituting chlorambucil for nitrogen mustard lessened acute nausea and vomiting but it seems unlikely to prevent secondary tumours or disturbances of fertility. In the same vein the Amsterdam Working Party for Childhood Tumours treated nine patients in stages I and II with tumours smaller than $4 \mathrm{~cm}$ with six MOPP cycles without radiotherapy (H Behrendt, B Van Bunningen, paper given at second international conference on malignant lymphoma, Lugano, Switzerland, 1984). All are in sustained complete remission with a median follow up of five years. Nine further patients with larger tumours were given the same drugs, sandwiched round local radiation of $25 \mathrm{~Gy}(2500$ rads). Only one child relapsed (outside the irradiated area) after 26 months, and he died of progressive disease. The remainder are free of disease with a follow up of 22-72 (median 50) months. These two reports show how successful chemotherapy can be in children with very early stages of Hodgkin's disease. The omission of staging laparotomy is therefore logical, and radiotherapy may reasonably be reduced or omitted. Problems of potential overtreatment of patients remain, however, and efforts need to be continued to remove potential carcinogenic substances from chemotherapy regimens.

Despite the astonishing success of the past 21 years small groups of patients may be identified who will fare less well. Young girls with bulky mediastinal masses are one such group, and at the other end of the age range treatment in patients over 60 still has a $60 \%$ failure rate. New therapeutic regimens must be developed for these high risk patients, and further clinical trials of multidisciplinary treatment (now the accepted norm) are mandatory. Tackling Hodgkin's disease in such a fashion has paid rich dividends. The lessons of the past two decades have provided oncology with an excellent model which is now being successfully applied to other forms of solid tumour. We hope that the next 21 years will see the control with multimodality treatment of the "big three" cancers-breast, lung, and colon.

J G McVIE Clinical research coordinator

R SOMERS

The Netherlands Cancer Institute,

Consultant physician

Antoni van Leeuwenhoek Huis,

Amsterdam

Correspondence to : $\mathrm{Dr} \mathrm{J}$ G McVie.

1 DeVita VT, Moxley JH III, Brace K, Frei E III. Intensive combination chemotherapy and xirradiation in the treatment of Hodgkin's disease. Proceedings of the American Association for Cancer Research 1965;6:15.

2 DeVita VT, Canellos P, Moxley JH. A decade of combination chemotherapy of advanced Hodgkin's disease. Cancer 1972;30:1495-504.

3 Santoro A, Bonadonna G, Bonfante V, Valagussa P. Alternating drug combinations in the treatment of advanced Hodgkin's disease. $N$ Engl f Med 1982;307:770-5.

4 Tubiana $M$, Henry-Amar $M$, Hayat $M$, et al. Prognostic significance of the number of involved areas in the early stages of Hodgkin's disease. Cancer 1984;54:885-94.

5 Cooper E, Pajak TF, Gottlieb AJ, et al. The effects of prior radiation therapy and age on the frequency and duration of complete remission among various four-drug treatments for advanced frequency and duration of complete remission among various four-d

6 Tester WJ, Kinsella TJ, Waller B, et al. Second malignant neoplasms complicating Hodgkin's disease: the National Cancer Institutc experience. Foumal of Clinical Oncology 1984;2:762-9.

7 Mauch PM, Weinstein H, Notnick L, Belli J, Cassady JR. An evaluation of long-term survival and treatment complications in children with Hodgkin's disease. Cancer 1983;51:925-32.

8 Robinson B, Kingston J, Nogueira Costa R, Malpas JS, Barrett A, McElwain TJ. Treatment of childhood Hodgkin's disease with chlorambucil, vinblastine, procarbazine and prednisolone (ChIVPP), and irradiation to sites of initial bulk disease. Arch Dis Child 1984;59:1162-7.

\section{Cigar and pipe smoking and the heart}

Some facts about smoking are not disputed. Cigarette smoking is a major causative risk factor for coronary heart disease, at least in communities with relatively high serum cholesterol concentrations ${ }^{1}$; and stopping cigarette smoking substantially reduces the risk of coronary attacks in healthy people ${ }^{23}$ and in survivors of myocardial infarction. ${ }^{4}$ Much less is known, however, about the possible adverse effects of pipe and cigar smoking in the genesis of coronary heart disease, nor do we have much information about the effect, if any, of pipe and cigar smoking on subsequent morbidity and mortality in survivors of myocardial infarction.

Our ignorance has been highlighted by a recent article by Jarvis $e t a l$, in which they analysed the data on smoking from the Multiple Risk Factor Intervention Trial (MRFIT). ${ }^{56}$ They argued that the changes in smoking habits in the "intervention" group in that trial may have been overestimated because cigar and pipe smokers were classed as non-smokers, despite the evidence that such smokers had raised serum thiocyanate concentrations, suggesting that they had inhaled nicotine, carbon monoxide, and other tobacco products. Given that Jarvis $e t$ al are correct in their interpretation, these inaccurate survey data might account, in part at least, for the relatively small differences that were observed in morbidity and mortality between the intervention and control groups in the MRFIT trial.

Epidemiological and clinical studies of the effects of pipe and cigar smoking as coronary risk factors have been hampered by the relatively small number of people who are regular pipe and cigar smokers, and because-in contrast to cigarette smokers - their smoking habits vary widely in terms of the quantity smoked and the extent of inhalation. Some population studies have reported a much smaller relative risk in pipe and cigar smokers than in cigarette smokers. The Surgeon General of the United States found a marginally raised risk from 1.02 to 1.40 in four studies of pipe smokers and three of cigar smokers compared with a 